\title{
Clinical characteristics of acute lymphoblastic leukemia in male and female patients: A retrospective analysis of $\mathbf{7 0 5}$ patients
}

\author{
SU-YI LI ${ }^{1-3}$, JIE-YU YE ${ }^{1,2}$, FAN-YI MENG ${ }^{1,2}$, CHUN-FU LI ${ }^{4}$ and MO YANG ${ }^{1,2}$ \\ ${ }^{1}$ Laboratory of Hematology, ${ }^{2}$ Department of Hematology, Nanfang Hospital, Southern Medical University, Guangzhou, \\ Guangdong 510515; ${ }^{3}$ Department of Hematology, First Affiliated Hospital of Zhengzhou University, \\ Zhengzhou, Henan 450052; ${ }^{4}$ Department of Paediatrics, Nanfang Hospital, \\ Southern Medical University, Guangzhou, Guangdong 510515, P.R. China
}

Received July 25, 2014; Accepted April 14, 2015

DOI: $10.3892 / 01.2015 .3202$

\begin{abstract}
The aim of the present study was to compare the clinical characteristics of acute lymphoblastic leukemia (ALL) that occurred in male and female patients at one institution in Southern China. The medical electronic records of Nanfang Hospital, affiliated to Southern Medical University, were searched for patients with a definite diagnosis of ALL that were diagnosed between January 1, 2001 and December 31, 2012. The clinical data of the patients were collected and analyzed. A total of 705 eligible patients were identified. The gender ratio of male to female patients was 1.84:1. The average ages at the time of diagnosis were 16.43 and 19.54 years for male and female patients, respectively $(\mathrm{P}=0.007)$. No significant differences were identified in the seasonal occurrence distribution, blood group distribution or ratio for the presence of the Ph chromosome between males and females. However, a higher incidence of T-cell type ALL was identified in males $(\mathrm{P}=0.023)$. The present study reveals that ALL demonstrates a male predominance, but similar clinical characteristics of ALL are present in males and females in Southern China.
\end{abstract}

\section{Introduction}

Acute lymphoblastic leukemia (ALL) is a malignant disorder of hematological progenitor cells that arises from the dysregulated clonal expansion of immature lymphoid progenitor cells that have encountered a series of catastrophic alternations within key regulatory genes (1). Similar to the majority of other cancers, the pathogenesis of ALL is complex, which probably originates from the complicated interactions between endogenous exposures, hereditary susceptibility and chance (2).

Correspondence to: Professor Mo Yang, Department of Hematology, Nanfang Hospital, Southern Medical University, 1838 Guangzhou North, Guangzhou, Guangdong 510515, P.R. China E-mail: yangm1091@hotmail.com

Key words: acute lymphoblastic leukemia, clinical characteristics, retrospective analysis
The complexity of ALL has also been reflected in the various clinical characteristics of the two genders, which demonstrates a regional and ethnic variance (3-7). The majority of previous studies on Chinese patients conveyed limited data regarding gender difference $(4,8-11)$. In addition, the patients in these studies were from Northern China, such as Beijing (12), Eastern China, such as Shanghai (5,6,9-11), and central China, such as Wuhan (10). To the best of our knowledge, only one study has reported the characteristics of ALL patients between 1985 and 1994 in Southern China, in Hong Kong (3). Updated studies are also limited in number (13-16).

The present study aimed to compare the clinical characteristics of acute lymphoblastic leukemia (ALL) in male and female patients from one institution in Southern China. In addition, the current study aims to provide clinical staff with additional information on the characteristics of ALL in China.

\section{Materials and methods}

Study design. The present study was designed as a retrospective analysis for the comparison between the clinical characteristics of ALL present in male and female patients at one institution in Southern China.

Data sources and search strategy. The patient data were collected from the Departments of Hematology and Pediatrics of Nanfang Hospital, affiliated to the Southern Medical University of Guangzhou (Guangzhou, Guangdong, China). The data search was performed using the medical electronic records in the aforementioned two departments. The index term 'acute lymphoblastic leukemia' was used and a time limit between January 1, 2001 and December 31, 2012 was set for the search. Subsequent to the initial retrieval of the patient records, the records were reviewed for their assessment eligibility.

Inclusion and exclusion criteria. Eligible patients were those with a definite diagnosis of ALL made at the aforementioned two departments, and with records that contained at least one aspect of the following information: Patient gender; age at the time of first diagnosis; month of the initial onset of ALL symptoms; ABO blood group; immunophenotype; and the results of a Philadelphia $(\mathrm{Ph})$ chromosome test, if available. 
Patients were excluded from the present study if ALL had been suspected, but final cell morphology and immunophenotype tests resulted in a different final diagnosis. The present study was approved by the Ethical Board of Nanfang Hospital.

Analysis of data. The overall clinical data of ALL was analyzed to identify the gender ratio, average age at the first diagnosis, month of the initial onset of ALL symptoms, distribution of $\mathrm{ABO}$ blood groups, positive ratio of $\mathrm{Ph}$ chromosome and immunophenotype distribution.

Statistical analysis. Statistical analysis was performed using SPSS 13.0 software (SPSS, Inc., Chicago, IL, USA). Continuous variables were expressed as the mean \pm standard deviation. Dichotomous variables were expressed as percentages. An independent sample $t$-test was performed to evaluate the differences in continuous variables between the two genders. The $\chi^{2}$ test was applied to assess the differences in dichotomous variables. $\mathrm{P} \leq 0.05$ was considered to indicate a statistically significant difference.

\section{Results}

Patients. A total of 2,758 patients were initially identified. Subsequent to reviewing the records, 705 eligible patients were finally included for the present study. The identification and inclusion process was illustrated in Fig. 1.

Gender ratio. The 705 eligable patients consisted of 457 males and 248 females, resulting in a male to female gender ratio of $1.84: 1$.

Average age at first diagnosis. As shown in Fig. 2, 363 patients $(51.49 \%)$ were $<15$ years old when diagnosed with ALL, with an incidence peak between 2 and 4 years of age. The overall average age at first diagnosis was 17.52 years. The average age at diagnosis was found to be significantly higher for female patients compared with male patients (19.54 vs. 16.43 years; $\mathrm{P}=0.007$; Table I).

Distribution of the month of presentation. The peak time for presentation with the initial onset of ALL symptoms was July, for male and female patients (Fig. 3). No significant difference in seasonal distribution was observed between the two genders (Table I).

Blood group distribution. A total of 685 patient records were suitable for analysis of the blood group distribution. As listed in Table I, blood group $\mathrm{O}$ was the most frequent blood type in ALL patients, not only overall (41.02\%), but also in male $(41.35 \%)$ and female $(40.42 \%)$ patients. However, no significant difference was identified in the distribution of blood group between the two genders (Table I).

Immunophenotype distribution. Out of the 705 ALL patients, 630 patients had medical records that were suitable for analysis of the immunophenotype in the two genders. A total of 490 ALL patients possessed B-cell ALL (77.78\%), accounting for the largest proportion of cases. No significant difference was identified in the immunophenotype distribution, with the
Total medical records initially $(\mathrm{n}=2758)$

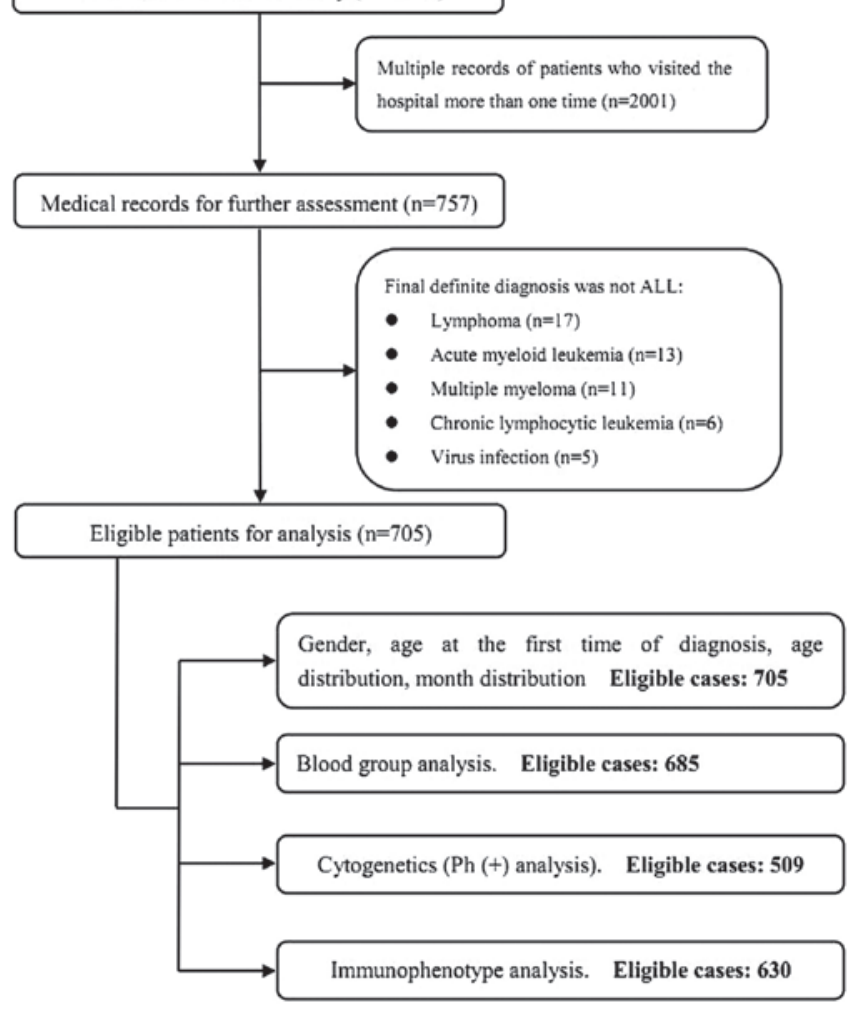

Figure 1. Flow chart of the process of study selection based on eligibility.

exception of a higher percentage of T-cell ALL in male patients $(15.80 \%)$ compared with female patients $(9.33 \%)(\mathrm{P}=0.023)$.

Philadelphia (Ph) chromosome. A total of 509 medical records contained the outcome of testing for the Ph chromosome. The present study found that a total of 90 ALL patients possessed the $\mathrm{Ph}$ chromosome, giving an overall $\mathrm{Ph}$ chromosome-positive rate of $17.68 \%$. The $\mathrm{Ph}$ chromosome-positive rates in males and females were 17.79 and $17.49 \%$, respectively ( $\mathrm{P}=0.931$; Table I).

\section{Discussion}

The findings of the present study based on 705 ALL patients in Southern China indicated a male predominance of ALL and a predilection of ALL to occur in children. Females appeared to be older at the time of the first diagnosis compared with males. The peak seasonal onset of ALL symptoms was in July. The O blood group and B-cell immunophenotype were the most frequent in ALL. No significant difference was identified in the distributions of seasonality and blood type, incidence of the $\mathrm{Ph}$ chromosome or immunophenotype distribution between the genders, but a significantly higher proportion of T-cell ALL was identified in male patients.

The present finding of the gender ratio indicated a male predominance, which is consistent with previous studies of Chinese ALL patients $(3,4,8-11,17-21)$. As shown in Table II, the gender ratio of ALL patients from various areas of China ranged between 1.37 (20) and 1.92 (3), indicating that regional differences exerted a minor influence on the gender predominance. With respect to other Asian countries, the majority of studies obtained similar outcomes of male predominance in 
Table I. Clinical data of 705 patients with acute lymphoblastic leukemia.

\begin{tabular}{|c|c|c|c|c|}
\hline Characteristics & Males, n (\%) & Females, n (\%) & Total, n (\%) & P-value \\
\hline Total & $457(100.00)$ & $248(100.00)$ & $705(100.00)$ & - \\
\hline $\begin{array}{l}\text { Average age at } \\
\text { diagnosis, years }\end{array}$ & $16.43 \pm 13.84$ & $19.54 \pm 15.12$ & $17.52 \pm 14.37$ & 0.007 \\
\hline \multicolumn{5}{|l|}{ Seasonal presentation } \\
\hline Total & $457(64.82)$ & $248(35.18)$ & $705(100.00)$ & - \\
\hline December-February & $120(26.26)$ & $59(23.79)$ & $179(25.39)$ & 0.472 \\
\hline March-May & $114(24.94)$ & $65(26.21)$ & $179(25.39)$ & 0.713 \\
\hline June-August & $118(25.82)$ & $71(28.63)$ & $189(26.81)$ & 0.421 \\
\hline September-November & $105(22.98)$ & $53(21.37)$ & $158(22.41)$ & 0.626 \\
\hline \multicolumn{5}{|l|}{ Blood group distribution } \\
\hline Total & $445(64.96)$ & $240(35.04)$ & $685(100.00)$ & - \\
\hline A & $124(27.86)$ & $65(27.08)$ & $189(27.59)$ & 0.827 \\
\hline $\mathrm{B}$ & $108(24.27)$ & $61(25.42)$ & $169(24.67)$ & 0.740 \\
\hline $\mathrm{O}$ & $184(41.35)$ & $97(40.42)$ & $281(41.02)$ & 0.813 \\
\hline $\mathrm{AB}$ & $29(6.52)$ & $17(7.08)$ & $46(6.72)$ & 0.777 \\
\hline \multicolumn{5}{|l|}{ Cytogenetic test } \\
\hline Total & $326(64.05)$ & $183(35.95)$ & $509(100.00)$ & - \\
\hline Ph chromosome (+) & $58(17.79)$ & $32(17.49)$ & $90(17.68)$ & 0.931 \\
\hline Ph chromosome(-) & $268(82.21)$ & $151(82.51)$ & $419(82.32)$ & - \\
\hline \multicolumn{5}{|c|}{ Immunophenotype distribution } \\
\hline Total & $405(64.29)$ & $225(35.71)$ & $630(100.00)$ & - \\
\hline B cell & $308(76.05)$ & $182(80.89)$ & $490(77.78)$ & 0.162 \\
\hline $\mathrm{T}$ cell & $64(15.80)$ & $21(9.33)$ & $85(13.49)$ & 0.023 \\
\hline Other & $33(8.15)$ & $22(9.78)$ & $55(8.73)$ & 0.487 \\
\hline
\end{tabular}

Ph chromosome, Philadelphia chromosome.

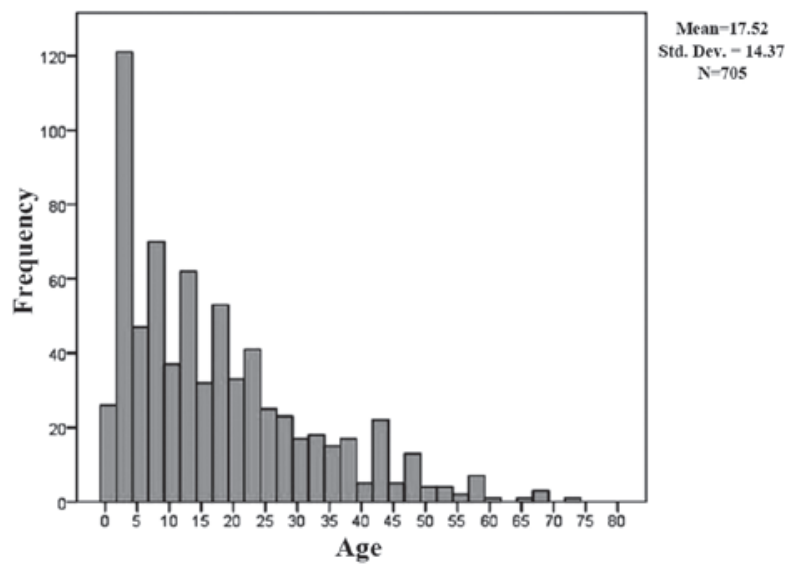

Figure 2. Age distribution of all acute lymphoblastic leukemia patients at the time of the initial diagnosis.

ALL, including male to female ratios of 1.88 in India (22), 1.49 in Indonesia (23), 1.70 in Jordan (24) and 1.85 in Iran (25). However, Matsumura et al (6) reported that the incidence of ALL in Japan demonstrated a female predominance. The present study considers that this difference may be associated with two factors. The first one lies in the sample size of the study by Matsumura et al $(\mathrm{n}=256)$, which may have affected

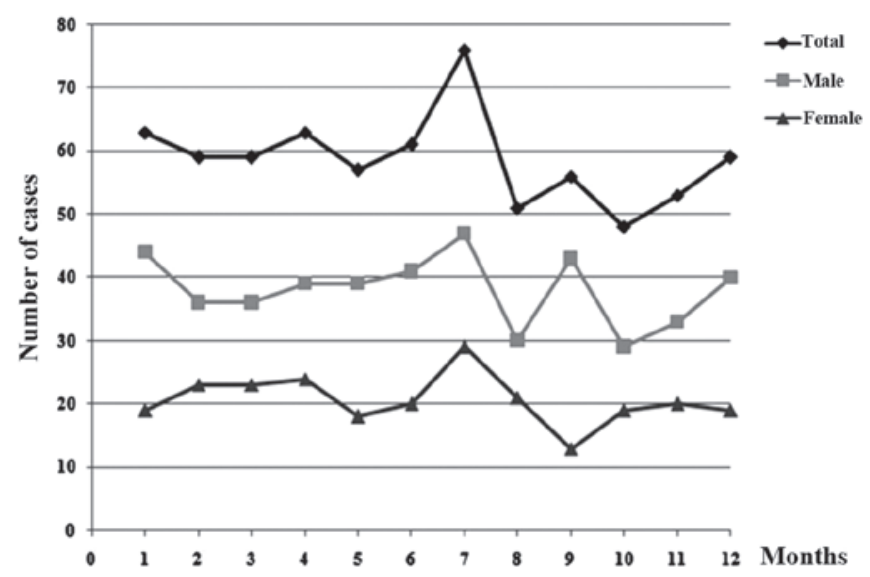

Figure 3. Month distribution of the initial appearance of acute lymphoblastic leukemia symptoms.

the outcome. The second factor is that the predominance may result from environmental pollution, including nuclear radiation.

The present study found more than one-half of the patients in the present study were under 15 years of age, particularly between 2 and 4 years of age, indicating that children and specifically infants are a high-risk group for the development 
of ALL. The present finding was in accordance with previous conclusions that $\sim 60 \%$ of patients in ALL were younger than 20 years of age (26-28). In addition, it was also observed that female patients were, on average, three years older than male patients at the time of the first diagnosis.

The month distribution for the initial onset of ALL symptoms found a peak presentation in July, overall and in each of the genders (Fig. 3), indicating that seasonality may affect the morbidity of ALL. However, controversy remains over the effect of seasonal factors in the incidence, diagnosis and treatment of ALL $(7,24,29)$. Gao et al (12) performed an international survey in Singapore, the USA and Sweden to provide evidence for the seasonal diagnosis of ALL. It was concluded that little evidence exsisted for a seasonal influence on ALL diagnosis. Kulkarni et al (30) indicated in a retrospective study that seasonality was not an independent prognostic factor and did not demonstrate a significant association with survival in univariate analysis. Therefore, future studies may focus on the influence of seasonality on ALL. Although the peak onset of ALL symptoms was in July, no significant differences in seasonal presentation were identified between the two genders.

Previous studies have reported that the ABO blood groups are closely associated with numerous tumors, including ovarian, endometrial and cervical cancer (31), nasopharyngeal carcinoma (32) and pancreatic cancer (33). Therefore, the present study investigated the association between the ABO blood groups and the incidence of ALL in Chinese patients. The present results indicated that the $\mathrm{O}$ blood group accounted for the highest proportion of cases, not only overall (41.02\%), but also individually in male $(41.35 \%)$ and female $(40.42 \%)$ patients. The AB blood group accounted for the lowest proportion of cases. The finding implies that $\mathrm{O}$ blood group may lead to a increased risk of ALL. Considering that a control group was not used in the present study, future studies should be based on a case-control design. Although the proportions of the ABO blood groups varied between the genders, no significant difference was identified in the distribution of the blood types. Disputes continue on the difference between the ABO blood group distributions of the two genders, which may be in assoication with various regions as well as different ethnicities. Jackson et al (34) found that the proportion of Malay male patients with the $\mathrm{O}$ blood group was significantly higher compared with the proportion of female patients, which was considered to explain the increased incidence of acute leukemia in males. Similar to the present outcomes, Alavi et al (35) reported that the most frequent blood type of paediatric patients with ALL in Iran was the O blood group, overall (56.5\%) and in male (56.7\%) and female (54.4\%) patients. There was also no statistical difference in blood type distribution between the genders.

An increasing number of genetic aberrations, which are considered to be predictive markers of prognoses, have been detected in the treatment of ALL. One of the most frequently used genetic aberrations is the $\mathrm{Ph}$ chromosome, also termed the BCR-ABL fusion gene, which may indicate a poor prognosis $(36,37)$. The present investigation of the $\mathrm{Ph}$ chromosome based on 509 Chinese patients found that the incidence of the $\mathrm{Ph}$ chromosome was $17.68 \%$, with no significant difference between the genders $(\mathrm{P}=0.931)$. The incidence of the $\mathrm{Ph}$ chromosome in China varied between $4.54 \%$ (17) and
$28.28 \%$ (18) (Table II). The present study hypothesizes that this wide range in the incidence of the $\mathrm{Ph}$ chromosome may be due to the various study objectives in the aforementioned studies. Studies that focused on paediatric patients with ALL usually obtained a positive ratio $<10 \%$, with the ratio mostly being $~ 5 \%(4,9,17,19,21)$. However, studies involving adult or mixed-age patients tended to find a positive ratio $>10 \%$, mostly $>15 \%(5,8,10,11,18)$. Therefore, adult ALL patients often demonstrated an increased incidence of the $\mathrm{Ph}$ chromosome compared with the pediatric patients with ALL. In the present study, the incidence of the $\mathrm{Ph}$ chromosome in adult patients was $20.76 \%$ (71 out of 342 patients), which was significantly higher than the incidence in paediatric patients $(5.23 \%)(\mathrm{P}=0.000)$. This may be an explanation for the worse prognosis of ALL in adult patients compared with paediatric patients.

In addition, the present study found an increased incidence of B-cell ALL (77.78\%), which was consistent with previously published studies performed in China. As can be observed in Table II, all published studies based on a Chinese population demonstrated an increased incidence in the B-cell immunophenotype, accounting for an average of $86.27 \%$ of cases (5739 of 6652 patients; range, 81.08-90.79\%). The immunophenotype of ALL may be another predictive factor of prognosis, as T-cell ALL usually demonstrates a worse prognosis compared with B-cell ALL (38). In the present study, a total of 85 patients were identified as possessing T-cell ALL, with a significantly higher percentage in males $(\mathrm{P}=0.023)$. Considering the limited sample size, additional studies should be performed.

There are two main limitations of the present study. No control group was used in the current study, which may reduce the reliability of the outcomes, particularly those with significant gender differences. In addition, patients were not sorted as children and adults, which may exert certain influences on the conclusions. However, the present study continues to be valuable, as it enriches the knowledge of the clinical characteristics of ALL in China.

In summary, the present study provides medical professionals with the clinical characteristics of ALL based on patients in Southern China. The present study indicates a male predominance and similar clinical characteristics of ALL between the two genders in Southern China. Whether significant gender differences reflected in the present study needs more clinical data to certify.

\section{References}

1. Pui CH: Childhood leukemias. N Engl J Med 332: 1618-1630, 1995.

2. Inaba H, Greaves M and Mullighan CG: Acute lymphoblastic leukaemia. Lancet 381: 1943-1955, 2013.

3. Ma SK, Chan GC, Ha SY, Chiu DC, Lau YL and Chan LC: Clinical presentation, hematologic features and treatment outcome of childhood acute lymphoblastic leukemia: a review of 73 cases in Hong Kong. Hematol Oncol 15: 141-149, 1997.

4. Gao F, Nordin P, Krantz I, Chia KS and Machin D: Variation in the seasonal diagnosis of acute lymphoblastic leukemia: evidence from Singapore, the United states and Sweden. Am J Epidemiol 162: 753-763, 2005.

5. Ni X, Shen ZX, Chen FY, Liang H, Lu FJ, Chen J, Wang C, Shao JB, Hou J, Zou SH and Wang JM: Trend in the incidence and geographic variations of acute lymphoblastic leukemia in Shanghai, China from 2002 to 2006. Chin Med J (Engl) 124: 2406-2410, 2011 
6. Matsumura T, Kami M, Yamaguchi T, Yuji K, Kusumi E, Taniguchi S, Takahashi S, Okada M, Sakamaki H, Azuma H, et al: Allogeneic cord blood transplantation for adult acute lymphoblastic leukemia: retrospective survey involving 256 patients in Japan. Leukemia 26: 1482-1486, 2012.

7. Goujon-Bellec S, Mollie A, Rudant J, Guyot-Goubin A and Clavel J: Time trends and seasonal variations in the diagnosis of childhood acute lymphoblastic leukaemia in France. Cancer Epidemiol 37: 255-261, 2013

8. Chen B, Wang YY, Shen Y, Zhang WN, He HY, Zhu YM, Chen HM, Gu CH, Fan X, Chen JM, et al: Newly diagnosed acute lymphoblastic leukemia in China (I): abnormal genetic patterns in 1346 childhood and adult cases and their comparison with the reports from Western countries. Leukemia 26: 1608-1616, 2012.

9. Gu LJ, Li J, Xue HL, Tang JY, Chen J, Zhao HJ, Ye H, Chen J and Pan C: Clinical outcome of children with newly diagnosed acute lymphoblastic leukemia treated in a single center in Shanghai, China. Leuk Lymphoma 49: 488-494, 2008.

10. Li X, Li J, Hu Y, Xie W, Du W, Liu W, Li X, Chen X, Li H, Wang J, et al: A comprehensive cytogenetic classification of 1466 Chinese patients with de novo acute lymphoblastic leukemia. Leuk Res 36: 720-726, 2012.

11. Mi JQ, Wang X, Yao Y,Lu HJ, Jiang XX, Zhou JF, Wang JH, Jiao B, Shen SH, Tang JY, et al: Newly diagnosed acute lymphoblastic leukemia in China (II): prognosis related to genetic abnormalities in a series of 1091 cases. Leukemia 26: 1507-1516, 2012.

12. Gao C, Zhao XX, Li WJ, Cui L, Zhao W, SG, Yue ZX, Jiao Y, Wu MY and Li ZG: Clinical features, early treatment responses and outcomes of pediatric acute lymphoblastic leukemia in China with or without specific fusion transcripts: a single institutional study of 1,004 patients. Am J Hematol 87: 1022-1027, 2012

13. Liu Z, Liu XL, Du QF, et al: Clinical characteristics and outcomes of 59 patients with acute lymphoblastic leukemia positive for BCR/ABL. Nan Fang Yi Ke Da Xue Xue Bao 29: 512-515, 2009 (In Chinese).

14. Gu L, Ma Z, Dong S, Kuang S, Tong Y and Xue H: Study on clinical and molecular biological characteristics of infant acute leukemia. Zhonghua Xue Ye Xue Za Zhi 21: 349-351, 2000 (In Chinese).

15. Gao SQ, Deng ZH, Jin SZ, Zhang SY, Zhang X and Wu GG: Study on the correlation between acute lymphoblastic leukemia and HLA genes in southern China Han population. Zhongguo Shi Yan Xue Ye Xue Za Zhi 13: 210-214, 2005 (In Chinese).

16. Tien HF, Wang CH, Lee FY, et al: Cytogenetic study of acute lymphoblastic leukemia and its correlation with immunophenotype and genotype. Cancer Genet Cytogenet 59: 191-198, 1992.

17. Guo Y, Chen YM, Zou Y, Chen XJ, Zhang L, Wang SC and Zhu XF: Biologic features of 688 cases of childhood acute leukemia-a single centre retrospective study. Zhongguo Dang Dai Er Ke Za Zhi 11: 793-796, 2009 (In Chinese).

18. Li Y, Zou D, Zhao Y, Mi Y, Wang J and Qiu L: Clinical characteristics and outcomes of adults with Philadelphia chromosome positive and/or bcr-abl positive acute lymphoblastic leukemia: a single center study from China. Leuk Lymphoma 51: 488-496, 2010.

19. Tong HX, Wang QS, Lu CW, Wang $\mathrm{H}$ and Liu ZG Immunophenotypes in 207 pediatric patients with ALL and theirs correlation with cytogenetics and clinical features. Zhongguo Shi Yan Xue Ye Xue Za Zhi 19: 696-701, 2011 (In Chinese).

20. Yang S: Retrospective analysis of Clinical data of 1039 patients with acute leukemia in the Hematology Department of Fujian Medical University Union Hopsital: Fujian Medical University, 2010.

21. Zeng HM, Guo Y, Yi XL, Zhou JF, An WB and Zhu XF: Large sample clinical analysis of patients with children acute leukemia in single center. Zhongguo Shi Yan Xue Ye Xue Za Zhi 19: 692-695, 2011 (In Chinese).
22. Rajalekshmy KR, Abitha AR, Anuratha N and Sagar TG: Time trend in frequency of occurrence of major immunophenotypes in paediatric acute lymphoblastic leukemia cases as experienced by Cancer Institute, Chennai, south India during the period 1989-2009. Indian J Cancer 48: 310-315, 2011.

23. Supriyadi E, Widjajanto PH, Purwanto I, Cloos J, Veerman AJ and Sutaryo S: Incidence of childhood leukemia in Yogyakarta, Indonesia, 1998-2009. Pediatr Blood Cancer 57: 588-593, 2011.

24. Abbasi S, Maleha F and Shobaki M: Acute lymphoblastic leukemia experience: epidemiology and outcome of two different regimens. Mediterr J Hematol Infect Dis 5: e2013024, 2013.

25. Karimi $M$ and Yarmohammadi $H$ : Seasonal variations in the onset of childhood leukemia/lymphoma: April 1996 to March 2000, Shiraz, Iran. Hematol Oncol 21: 51-55, 2003.

26. Hunger SP, Lu X, Devidas M, Camitta BM, Gaynon PS, Winick NJ, Reaman GH and Carroll WL: Improved survival for children and adolescents with acute lymphoblastic leukemia between 1990 and 2005: a report from the children's oncology group. J Clin Oncol 30: 1663-1669, 2012.

27. Pui CH, Robison LL and Look AT: Acute lymphoblastic leukaemia. Lancet 371: 1030-1043, 2008.

28. Stanulla M and Schrappe M: Treatment of childhood acute lymphoblastic leukemia. Semin Hematol 46: 52-63, 2009.

29. Nyari TA, Kajtar P, Bartyik K, Thurzo L, McNally R and Parker L: Seasonal variation of childhood acute lymphoblastic leukaemia is different between girls and boys. Pathol Oncol Res 14: 423-428, 2008.

30. Kulkarni KP and Marwaha RK: Seasonality in diagnosis of childhood acute lymphoblastic leukemia: impact on disease presentation, survival outcome and resources. J Pediatr Hematol Oncol 35: 81-82, 2013.

31. Yuzhalin AE and Kutikhin AG: ABO and Rh blood groups in relation to ovarian, endometrial and cervical cancer risk among the population of South-East Siberia. Asian Pac J Cancer Prev 13: 5091-5096, 2012.

32. Sheng L, Sun X, Zhang L and Su D: ABO blood group and nasopharyngeal carcinoma risk in a population of Southeast China. Int J Cancer 133: 893-897, 2013.

33. Pelzer U, Klein F, Bahra M, Sinn M, Dorken B, Neuhaus P, Meyer $\mathrm{O}$ and Riess $\mathrm{H}$ : Blood group determinates incidence for pancreatic cancer in Germany. Front Physiol 4: 118, 2013.

34. Jackson N, Menon BS, Zarina W, Zawawi N and Naing NN: Why is acute leukemia more common in males? A possible sex-determined risk linked to the ABO blood group genes Ann Hematol 78: 233-236, 1999.

35. Alavi S, Ashraf H, Rashidi A, Hosseini N, Abouzari M and Naderifar M: Distribution of ABO blood groups in childhood acute leukemia. Pediatr Hematol Oncol 23: 611-617, 2006

36. Arico M, Valsecchi MG, Camitta B, Schrappe M, Chessells J, Baruchel A, Gaynon P, Silverman L, Janka-Schaub G, Kamps W, et al: Outcome of treatment in children with Philadelphia chromosome-positive acute lymphoblastic leukemia. N Engl J Med 342: 998-1006, 2000.

37. Pieters R: Infant acute lymphoblastic leukemia: Lessons learned and future directions. Curr Hematol Malig Rep 4: 167-174, 2009.

38. Van Vlierberghe P, Pieters R, Beverloo HB and Meijerink JP. Molecular-genetic insights in paediatric T-cell acute lymphoblastic leukaemia. Br J Haematol 143: 153-168, 2008. 